\title{
Corrigendum: Iron-catalysed cross-coupling of organolithium compounds with organic halides
}

\author{
Zhenhua Jia, Qiang Liu, Xiao-Shui Peng \& Henry N.C. Wong
}

Nature Communications 7:10614 doi: 10.1038/ncomms10614 (2016); Published 5 Feb 2016; Updated 14 Jun 2016

Previous work by Cahiez et al. 2007 describing iron-catalysed cross-coupling of Grignard reagents was inadvertently omitted from the reference list of this Article. This work should have been cited following the sentence 'This catalytic system developed by Nakamura had been employed in cross-coupling reactions with Grignard reagents and arylzinc reagents'. Additionally, the formation of the TMEDA/iron(III) chloride complex was incorrectly attributed; the statement 'Therefore, the complex of TMEDA with iron(III) chloride was prepared according to Nakamura's procedure' should read 'Therefore, the complex of TMEDA with iron(III) chloride was prepared according to Cahiez's procedure (Cahiez et al. 2007)'.

Cahiez, G., Habiak, V., Duplais, C. \& Moyeux, A. Iron-catalyzed alkylations of aromatic Grignard reagents. Angew. Chem. Int. Ed. 46, 4364-4366 (2007).

This work is licensed under a Creative Commons Attribution 4.0 International License. The images or other third party material in this article are included in the article's Creative Commons license, unless indicated otherwise in the credit line; if the material is not included under the Creative Commons license, users will need to obtain permission from the license holder to reproduce the material. To view a copy of this license, visit http://creativecommons.org/licenses/by/4.0/ 